\title{
Impaired clearance of apoptotic cardiocytes is linked to anti-SSA/Ro and -SSB/La antibodies in the pathogenesis of congenital heart block
}

\author{
Robert M. Clancy, ${ }^{1}$ Petra J. Neufing, ${ }^{2}$ Ping Zheng, ${ }^{1}$ Marguerita O'Mahony, ${ }^{1}$ Falk Nimmerjahn, ${ }^{3}$
} Tom P. Gordon, ${ }^{2}$ and Jill P. Buyon 1

\begin{abstract}
1Department of Medicine, Division of Rheumatology, New York University School of Medicine, New York, New York, USA. 2Department of Immunology, Allergy, and Arthritis, Flinders Medical Centre, Bedford Park, South Australia, Australia. 3Laboratory of Molecular Genetics and Immunology, Rockefeller University, New York, New York, USA
\end{abstract}

\begin{abstract}
The role of cardiocytes in physiologic removal of apoptotic cells and the subsequent effect of surface binding by anti-SSA/Ro and -SSB/La antibodies was addressed. Initial experiments evaluated induction of apoptosis by extrinsic and intrinsic pathways. Nuclear injury and the translocation of SSA/Ro and SSB/La antigens to the fetal cardiocyte plasma membrane were common downstream events of Fas and TNF receptor ligation, requiring caspase activation. As assessed by phase-contrast and confirmed by confocal microscopy, coculturing of healthy cardiocytes with cardiocytes rendered apoptotic via extrinsic pathways revealed a clearance mechanism that to our knowledge has not previously been described. Cultured fetal cardiocytes expressed phosphatidylserine receptors (PSRs), as did cardiac tissue from a fetus with congenital heart block (CHB) and an age-matched control. Phagocytic uptake was blocked by anti-PSR antibodies and was significantly inhibited following preincubation of apoptotic cardiocytes with chicken and murine anti-SSA/Ro and -SSB/La antibodies, with IgG from an anti-SSA/Ro- and-SSB/La-positive mother of a CHB child, but not with anti-HLA class I antibody. In a murine model, anti-Ro60 bound and inhibited uptake of apoptotic cardiocytes from wild-type but not Ro60-knockout mice. Our results suggest that resident cardiocytes participate in physiologic clearance of apoptotic cardiocytes but that clearance is inhibited by opsonization via maternal autoantibodies, resulting in accumulation of apoptotic cells, promoting inflammation and subsequent scarring.
\end{abstract}

\section{Introduction}

In a fetus diagnosed with isolated congenital heart block (CHB), evaluation of the maternal serum almost invariably reveals the presence of antibodies to the ribonucleoproteins SSA/Ro and/ or SSB/La, irrespective of the maternal health status $(1,2)$. While the clinical association between serologic marker and fetal disease is strong, the precise target of the antibody and the mechanism whereby an extracellular antibody physically meets a normally sequestered intracellular antigen are less well understood. In vitro and in vivo studies suggest that one pathologic cascade linking antibodies to eventual scarring may be initiated via apoptosis. The translocation of SSA/Ro and SSB/La to apoptotic blebs was first reported in cultured human keratinocytes following UV irradiation (3) and subsequently identified in cultured human fetal cardiocytes exposed to staurosporine (4). Additional support for the role of apoptosis in provoking cardiac injury was provided by immunohistochemical analysis of hearts from several fetuses dying with CHB (5) as well as by recent studies employing a mouse model of CHB (6-8). Remarkably, apoptosis was not only detectable but exaggerated more

Nonstandard abbreviations used: ANA, antinuclear antibodies; $\mathrm{CHB}$, congenital heart block; LDH, lactate dehydrogenase; pHEMA, poly(2-)hydroxyethylmethacrylate; PS, phosphatidylserine; PSR, PS receptor; RFU, relative fluorescence unit(s); RNP, ribonucleoprotein; $\mathrm{ScFv}$, single-chain variable fragment.

Conflict of interest: The authors have declared that no conflict of interest exists. Citation for this article: J. Clin. Invest. 116:2413-2422 (2006). doi:10.1172/JCI27803. than 30-fold in septal tissue of CHB hearts, suggesting a potential defect in clearance.

Cell death is programmed in various cell types following binding of ligands such as TNF- $\alpha$ and FasL to their respective receptors, Fas and TNF receptor 1 (TNFR1). Signaling by these death receptors promotes the formation of homotrimeric complexes and the recruitment of adaptor proteins such as Fas-associated death domain protein (FADD) (9) or TNFR-associated death domain protein (TRADD) (10) and subsequent activation of caspase-8 (11, 12). The activation of caspase- 8 enables activation of downstream effector caspases, including caspase-3, culminating in cell death $(13,14)$. Different apoptosis-inducing stimuli lead to identical characteristic morphologic and biochemical changes, but limited data exist to extend these findings to cellular redistribution of nuclear antigens in human fetal cardiocytes. SSA/Ro-SSB/La may be distinguished from other self antigens in that during apoptosis, there is not only translocation but accessibility to extracellular antibodies $(4,15)$. At least one other nuclear antigen, lamin B1, has been shown to undergo cellular redistribution; however, it was entirely enclosed within the apoptotic bleb membrane and was not surface bound by antibody (16).

Tissues undergoing remodeling must be protected from pathologic consequences and/or inflammation (17-21). Whereas the majority of studies on apoptotic cell removal have focused on professional phagocytes such as macrophages, the participation of resident cardiocytes themselves in this process remains to be investigated. Precedent for this consideration derives from studies 


\section{Table 1}

SSA/Ro-SSB/La antigens exposed at the surface of apoptotic cardiocytes are bound by anti-SSA/Ro- and -SSB/La-positive IgG and antiRo60/Ro52/La48 monoclonal antibodies

\begin{tabular}{lccc} 
& \multicolumn{3}{c}{$\begin{array}{c}\text { Percentage of cells bound by antibody } \\
\text { Proliferating }\end{array}$} \\
Apoptotic \\
IgG or mAb & Nonpermeabilized & $\begin{array}{l}\text { Permeabilized } \\
\text { Normal control IgG }\end{array}$ & \\
CHB-1 IgG & $5.4 \pm 2.3$ & $3.4 \pm 3.3$ & $3.7 \pm 2.5$ \\
ANA-1 IgGD & $7.6 \pm 2.8$ & $87.5 \pm 13.1 \mathrm{C}$ & $48.5 \pm 11.3$ \\
RNP-1 IgGE & 2.7 & 55.8 & $3.0 \pm 2.5$ \\
Anti-HA & 5.0 & 77.3 & $9.3 \pm 3.9$ \\
ScFv 60.1 & $0.4 \pm 0.4$ & $3.6 \pm 1.0$ & $2.8 \pm 3.0$ \\
ScFv 60.2 & $6.6 \pm 5.3$ & $78.6 \pm 7.5$ & $43.5 \pm 12.7$ \\
ScFv 60.3 & $5.9 \pm 4.9$ & $86.9 \pm 7.1$ & $31.0 \pm 9.3$ \\
ScFv 60.4 & $6.7 \pm 5.1$ & $95.4 \pm 11.3$ & $56.0 \pm 13.7$ \\
ScFv 60.5 & $3.0 \pm 2.4$ & $67.1 \pm 6.3$ & $8.6 \pm 5.5$ \\
ScFv 52.1 & $3.1 \pm 3.0$ & $65.0 \pm 5.5$ & $43.5 \pm 4.0$ \\
ScFv 52.2 & $8.6 \pm 7.5$ & $93.5 \pm 12.0$ & $3.0 \pm 0.9$ \\
ScFv 52.3 & $2.3 \pm 2.7$ & $83.8 \pm 11.0$ & $23.3 \pm 12.4$ \\
ScFv 52.4 & $1.6 \pm 1.5$ & $63.9 \pm 6.6$ & $3.3 \pm 1.3$ \\
ScFv 48.1 & $3.0 \pm 3.3$ & $73.0 \pm 8.3$ & $2.3 \pm 0.6$ \\
ScFv 48.2 & $9.5 \pm 5.1$ & $94.4 \pm 15.5$ & $64.5 \pm 9.4$ \\
& $4.1 \pm 3.3$ & $54.4 \pm 7.5$ & $79.3 \pm 4.0$
\end{tabular}

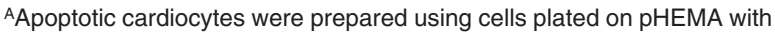
TNF- $\alpha$. Apoptotic cardiocytes as well as intact cardiocytes were stained under nonpermeabilized conditions. Digitonin-permeabilized fetal cardiocytes served as positive controls. For each test, the percentage of positive cells are number of cells in gate that exceeded the 95th percentile of stain for isotype control. ${ }^{B}$ Human IgG isolated from a mother whose child has CHB (reactivity to La48, Ro52, Ro60). Clt was anticipated that since all cells contain Ro/La, 100\% of cells would stain positively with antibodies to SSA-Ro/SSB-La; however, a recovery (percentage of cells bound by antibody) of less than $100 \%$ was observed in most cases. This result indicates that Ro/La antigens were lost during treatment with digitonin or that the commercial kit has limitations for the analysis of nuclear proteins. The anti-CD95 data, with analysis for binding of 2 of the 11 antibodies, is described in Results. ${ }^{\text {DHuman }} \operatorname{lgG}$ isolated from a patient with SLE whose serum contains anti-nuclear antibodies but not antiSSA/Ro and -SSB/La antibodies. EHuman IgG isolated from a patient with SLE whose serum contains anti-U1RNP antibodies but not anti-SSA/Ro and -SSB/ La antibodies. For proliferating cells, $n=4$; for apoptotic cells, $n \geq 5$.
\end{abstract}

in rodents that demonstrate that cardiac cells themselves are capable of engulfing apoptotic cells $(22,23)$. Perhaps the unanticipated accumulation of apoptotic cardiocytes seen in histologic sections from $\mathrm{CHB}$ hearts is secondary to impaired apoptotic cell clearance by adjacent cardiocytes. Deregulation of apoptosis may result in pathologic conditions characterized by inflammation and subsequent scarring $(24,25)$. Accordingly, this study first examined extrinsic and intrinsic death pathways in fetal cardiocytes to verify that the translocation of SSA/Ro-SSB/La occurs in all cells undergoing apoptosis independent of the "apoptotic trigger." Having identified pathways to apoptosis and antigen translocation, we designed experiments to test the hypothesis that healthy fetal cardiocytes are involved in physiologic removal of apoptotic cells and that surface binding by anti-SSA/Ro and -SSB/La antibodies inhibits this process.

\section{Results}

Surface accessibility of SSA/Ro-SSB/La on buman fetal cardiocytes is independent of the apoptotic pathway induced. In order to test the hypothesis that SSA/Ro-SSB/La is a ligand in the removal of apoptotic cells, initial experiments were designed to confirm that (a) SSA/Ro and SSB/La are specifically recruited from the nucleus and translocated to the cell surface of cultured fetal cardiocytes regardless of the method used to induce apoptosis; and (b) surface accessibility is the direct consequence of intracellular caspase activation. As previously demonstrated, an IgG fraction isolated from a mother (CHB-1) with antibodies reactive against La48, Ro52, and Ro60, whose child has CHB, bound apoptotic cells (Table 1 ). To circumvent the ambiguity in using IgG fractions from a patient with polyclonal reactivity, 11 monoclonal single-chain variable fragment $(\mathrm{ScFv})$ antibody fragments were generated from a phage display library and characterized by reactivity on ELISA with the respective human recombinant antigens. The $\mathrm{ScFv}$ antibody fragments bound to cognate antigen with high affinities. For example, the SSA-Ro/60 affinity constants of ScFv monoclonals were determined using surface plasmon resonance imaging (Figure $1 \mathrm{C})$. The association $\left(K_{\mathrm{a}}\right)$ and dissociation constants $\left(K_{\mathrm{d}}\right)$ of $\mathrm{ScFv} 60.1,60.2,60.3$, and 60.4 for recombinant SSA-Ro/60 were $3.4 \times 10^{7}, 3.1 \times 10^{7}, 1.1 \times 10^{8}$, and $3.0 \times 10^{7} \mathrm{M}^{-1}\left(K_{\mathrm{a}}\right)$ and $2.9 \times 10^{-8}, 3.2 \times 10^{-8}, 9.4 \times 10^{-9}$, and $3.3 \times 10^{-8} \mathrm{M}\left(K_{\mathrm{d}}\right)$.

Each antibody was reactive with permeabilized human fetal cardiocytes but not nonpermeabilized nonapoptotic cells as assessed by FACS staining (Table 1 and Figure 1A; Figure 1A shows data for 60.1 and 60.4 only). To assess binding of these monoclonal antibodies to the surface of apoptotic human fetal cardiocytes, fetal cardiocytes were isolated and separately cultured under standard conditions or plated on poly(2-)hydroxyethylmethacrylate (pHEMA;

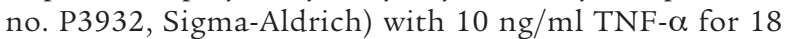
hours at $37^{\circ} \mathrm{C}$ as described previously (26). Cell supernatants were analyzed for lactate dehydrogenase (LDH) to exclude necrosis, while apoptosis was assessed by antiactive caspase-3 antibody FACS analysis (apoptotic index was reported as the percentage of positive cells [>95th percentile of isotype control]). Treatment using TNF- $\alpha$ with pHEMA resulted in $44.7 \% \pm 7.9 \%$ active caspase- 3 -positive cells, compared with $4.9 \% \pm 1.4 \%$ in untreated proliferating cardiocytes $(P<0.001$, apoptotic versus proliferating). These cells had not undergone necrosis with loss of membrane integrity, as determined by the absence of significant LDH release ( $<6 \%$ total; data not shown). Four of the 5 monoclonal anti-60 antibodies (m60.1, m60.2, m60.3, m60.5) stained positive for nonpermeabilized annexin $\mathrm{V}$, indicating that they were apoptotic (Table 1 and Figure 1B). The absence of reactivity by $\mathrm{ScFv} 60.4$ was not due to a decrease in binding affinity (Figure 1C) but may reflect a difference in surface accessibility of an epitope on the apoptotic cells. In addition, 1 of 4 anti-Ro52 (52.2) and 2 of 2 anti-La $(48.1,48.2)$ monoclonal antibodies bound the apoptotic cardiocytes (Table 1 ).

Further specificity of the binding reactivity to components of the SSA/Ro-SSB/La complex was provided by the evaluation of additional IgG fractions (absent reactivity to La48, Ro52, or Ro60). Specifically, there was no staining with IgG fractions (equivalent IgG concentrations to that used for CHB-1) isolated from the serum of a normal healthy donor, a patient with SLE who had anti-U1 ribonucleoprotein (anti-U1RNP) antibodies, or a patient with SLE and antinuclear antibodies (ANA) only (Table 1). Specificity of binding of the $\mathrm{ScF} v$ to the cardiocytes rendered apoptotic via extrinsic pathway activation was addressed. Preincubation of apoptotic cells with IgG of the CHB mother (CHB-1) 


\section{A}
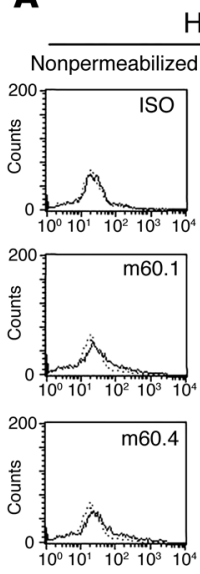

Healthy
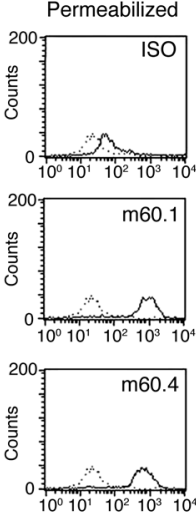
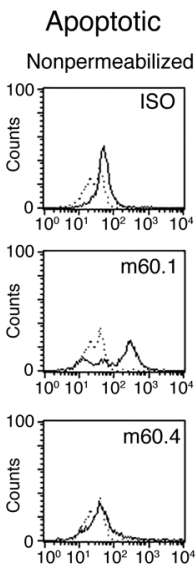

B Annexin V (FITC) ScFv (PE)
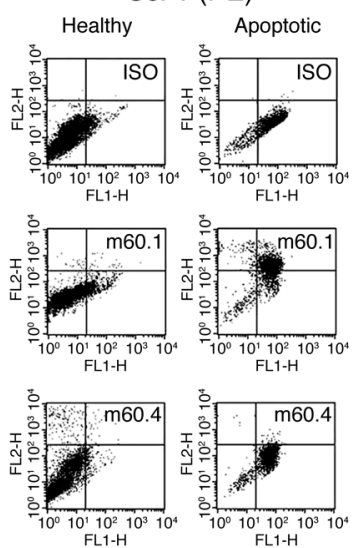
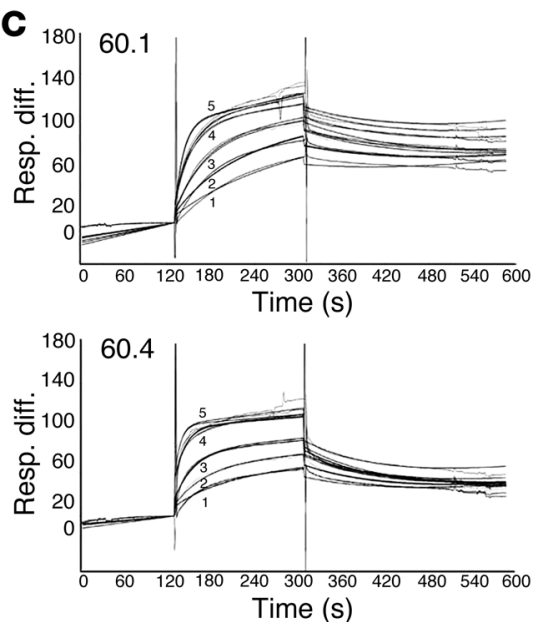

Figure 1

Reactivity and binding activity of monoclonal antibodies ScFv 60.1 and 60.4. Apoptotic and intact cardiocytes were single and double stained using monoclonal antibodies (ScFv) to evaluate accessibility of SSA/Ro60. Apoptotic cardiocytes were prepared by plating fetal human cardiocytes on pHEMA plus TNF- $\alpha\left(10 \mathrm{ng} / \mathrm{ml}, 18\right.$ hours, $\left.37^{\circ} \mathrm{C}\right)$. Representative FACS data to evaluate the binding of different monoclonal antibodies to cell preparations are shown in $\mathbf{A}$ and $\mathbf{B}$ (see also Table 1). (A) Apoptotic cardiocytes as well as intact cardiocytes (normal culture conditions) and digitonin-permeabilized and nonpermeabilized fetal cardiocytes were single stained (isotype control [ISO] and 2 anti-Ro60 monoclonal antibodies, m60.1 and m60.4). (B) Intact and apoptotic cardiocytes were double stained using annexin V-FITC and a second-stage PE antibody reporting binding of isotype or anti-Ro60 monoclonal antibody (m60.1, m60.4). FL1 ( $x$ axis) and FL2 ( $y$ axis) indicate the binding of annexin and ScFv antibody, respectively. (C) Real-time recording of the interaction between SSA Ro60 and the monoclonal antibodies 60.1 (top) and 60.4 (bottom) as assessed by surface plasmon resonance imaging. In each tracing, a time interval was used to measure association (from 125 to 300 seconds) and dissociation (from 330 to 600 seconds) at each concentration of monoclonal antibody. The concentrations used were $31.3 \mathrm{nM}$, $62.7 \mathrm{nM}, 125 \mathrm{nM}, 250 \mathrm{nM}$, and $500 \mathrm{nM}$ (tracings 1-5, respectively). Note that, for the association, saturation was achieved at the $250 \mathrm{nM}$ and $500 \mathrm{nM}$ concentrations. Resp. diff., response difference.

reduced the mean binding of $\mathrm{ScFv} 60.1$ from $50.7 \%$ to $26.5 \%$; of $\mathrm{ScFv} 52.2$ from $19.2 \%$ to $10.9 \%$; and of $\mathrm{ScFv} 48.1$ from $88.1 \%$ to $66.7 \%$ (data not shown).

Human fetal cardiocytes exposed to anti-CD95, a surrogate of Fas ligand (18 hours; see Methods), expressed active caspase- 3 (not shown). Cells were then incubated in the absence or presence of the $\mathrm{ScFv}$ monoclonal antibodies described, each under nonpermeabilizing conditions. The percentages of apoptotic cells staining positive for antibodies $\mathrm{m} 60.1$ and $\mathrm{m} 48.1$ were $60.5 \pm 6.9$ and $55.9 \pm 5.5$, respectively (versus $0.2 \pm 0.2$, isotype control).

Having confirmed surface expression of components of the SSA/Ro-SSB/La complex on the apoptotic cells via extrinsic pathway activation, it was next determined whether this expression was held in common regardless of the mechanism. As expected, treatment of human fetal cardiocytes with staurosporine (7 hours, $0.5 \mu \mathrm{M}$ ) led to active caspase-3-positive cells (data not shown). In parallel with extrinsic pathway activation, the percentages of apoptotic cells staining positive for antibodies $\mathrm{m} 60.1$ and $\mathrm{m} 48.1$ were $61.9 \pm 8.7$ and $67.0 \pm 6.3$, respectively (versus $0.4 \pm 0.4$, isotype control). In parallel with the results on induction of apoptosis with extrinsic activation, the IgG-

\section{Figure 2}

Human fetal cardiac cells remove autologous apoptotic cells. Cardiac cells were incubated with or without autologous apoptotic cells ( 5 hours or 18 hours, $37^{\circ} \mathrm{C}$ ). (A) Cells were fixed, permeabilized, and stained using the TUNEL-peroxidase assay. (B) Confocal analysis of a single cell double-labeled with TUNELFITC (green) and anti- $\alpha$-sarcomeric actinin (red) to identify the phagocytosing cell as a cardiocyte.
RNP fraction did not bind cardiocytes rendered apoptotic using staurosporine (data not shown).

TNF- $\alpha$-induced apoptosis and phosphatidylserine (PS) externalization in fetal cardiocytes were effectively blocked by preincubating cardiocytes with a broad-spectrum caspase inhibitor, Z-VAD-FMK (52.2 versus 91.8 mean relative fluorescence units [RFU] of anti-human IgG-FITC, with or without inhibitor, respectively; $P=0.008 ; n=4)$. In parallel, the binding of IgG from a CHB mother (CHB-1) to apoptotic cells was commensurately reduced when $Z$-VAD-FMK was used (117.8 versus 243.5 RFU; $P=0.045)$. Healthy IgG or isotype controls did not associate with the apoptotic cell surface.

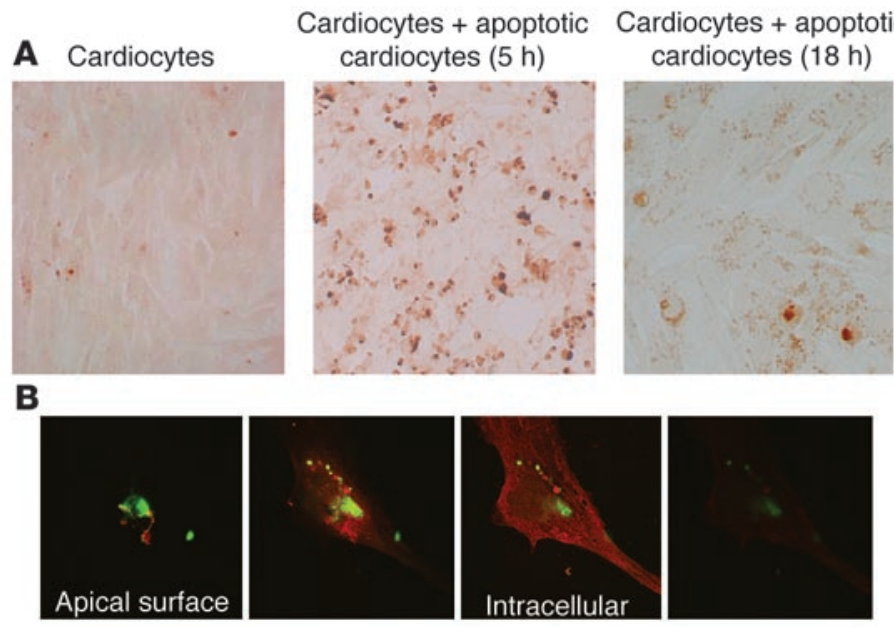




\section{Table 2}

Cotreatment of apoptotic cardiac cells with monoclonal antibodies (ScFv) to SSA/Ro-SSB/La inhibited PS-dependent engulfment by neighboring cardiocytes

\begin{tabular}{|c|c|c|}
\hline $\begin{array}{l}\text { Apoptotic cell } \\
\text { stain }^{A}\end{array}$ & $\begin{array}{l}\% \text { Cells involved in engulfment } \\
\text { of apoptotic cells }\end{array}$ & $P$ \\
\hline None & $49.5 \pm 8.5$ & \\
\hline Normal control IgG & $53.7 \pm 4.3$ & \\
\hline CHB-1 IgGB & $16.5 \pm 4.0$ & 0.008 \\
\hline CHB-2 IgGB & $14.5 \pm 4.3$ & 0.016 \\
\hline ANA-1 IgGC & $51.3 \pm 7.2$ & \\
\hline RNP-1 IgGD & $52.4 \pm 6.2$ & \\
\hline Anti-HA & $51.3 \pm 3.6$ & \\
\hline ScFv 60.1 & $18.6 \pm 2.0$ & 0.016 \\
\hline ScFv 60.2 & $8.1 \pm 1.9$ & 0.036 \\
\hline ScFv 60.3 & $11.0 \pm 5.0$ & 0.036 \\
\hline ScFv $60.4^{\mathrm{E}}$ & $44.1 \pm 6.8$ & \\
\hline ScFv 52.1 & $39.2 \pm 3.7$ & \\
\hline ScFv 52.2 & $24.3 \pm 4.3$ & 0.016 \\
\hline ScFv 52.3 & $58.8 \pm 3.4$ & \\
\hline ScFv 52.4 & $43.4 \pm 12.8$ & \\
\hline ScFv 48.1 & $9.7 \pm 7.4$ & 0.036 \\
\hline ScFv 48.2 & $16.2 \pm 5.1$ & 0.008 \\
\hline $3 B 9 F$ & 32.0 & $N D^{G}$ \\
\hline $\mathrm{SW}^{\mathrm{H}}$ & 24.5 & ND \\
\hline Sal-5। & 54.0 & ND \\
\hline Anti-CD32 & 47.0 & ND \\
\hline Anti-PSR, 1:50 & 22.0 & ND \\
\hline Anti-PSR, 1:100 & 37.6 & ND \\
\hline Anti-PSR, 1:200 & 53.0 & ND \\
\hline Anti-HLA class 1 & 57.5 & ND \\
\hline
\end{tabular}

\begin{abstract}
AApoptotic cardiocytes were prepared using cells plated on pHEMA with TNF $\alpha$. Treatment of intact cardiocytes with apoptotic cardiocytes (2:1 ratio, 5 hours) was followed by washing to remove nonadherent apoptotic cells. The remaining apoptotic cells, which were tethered to intact cardiocytes, were treated with TUNEL reagents for their identification. The percentage of cells involved in engulfment of apoptotic cells (reported as mean values) was determined by dividing the number of cells with bound or internalized apoptotic cells by the total number of cells. $P$ values compare apoptotic cell stain with no addition (i.e., apoptotic cells without antibody [None]). Note: $n=6$ for all experiments, except ND (where $n=2$ ). BHuman IgG isolated from 2 mothers of CHB-children (reactivity to La48, Ro52, Ro60). CHuman IgG isolated from a patient with SLE whose serum contains anti-nuclear antibodies but not anti-SSA/Ro and -SSB/La antibodies. DHuman IgG isolated from a patient with SLE whose serum contains anti-U1RNP antibodies but not anti-SSA/Ro and -SSB/La antibodies. $E P=0.016$ for condition 60.1 versus 60.4 . $\mathrm{FmAb}$ reactive with the $\mathrm{hLaA}$ subfragment. GND, not determined $(n=2)$. ${ }^{H}$ Ab reactive with the hLaC subfragment. 'Isotype control.
\end{abstract}

Healthy (proliferating) cardiocytes are capable of phagocytosing apoptotic cardiocytes. A functional assay was established to test the capacity of human fetal cardiac cells to engulf apoptotic cells. For these experiments, cardiocytes were rendered apoptotic by plating on pHEMA with $10 \mathrm{ng} / \mathrm{ml} \mathrm{TNF}-\alpha$ for 18 hours at $37^{\circ} \mathrm{C}$ as described above. The apoptotic cells were then incubated with autologous proliferating cardiocytes $\left(5-18\right.$ hours, $\left.37^{\circ} \mathrm{C}\right)$. Cells were fixed, permeabilized, and stained using the TUNEL assay (tA). As indicated by the TUNEL-peroxidase stain, the interaction between apoptotic cells and neighboring intact cardiocytes was characterized by tethering and engulfment after 5 hours. At 18 hours, the apoptotic cells appeared to be highly fragmented, uniform in size, and perinuclear in distribution (Figure 2A). The results of these coculture engulfment experiments were consistent among cardiocytes isolated from 11 different fetal hearts of gestational ages 18-24 weeks. Confocal microscopy with double labeling (anti- $\alpha$-sarcomeric actinin [red] to confirm that the phagocytosing cells were cardiocytes; and TUNEL-FITC [green] to identify apoptotic cells) confirmed the phagocytosis of the apoptotic cells by the cardiocytes (Figure 2B).

The next set of experiments addressed the identification of cardiocyte receptor(s) that might be responsible for uptake of apoptotic cells. As assessed by RT-PCR and FACS, human fetal cardiac cells expressed PS receptor (PSR) but not Fc $\gamma$ RIIa and -IIc (Figure 3). Preincubation of the proliferating cardiocytes with anti-PSR antibodies markedly attenuated the apoptotic cell uptake in a dose-dependent manner (Table 2). In contrast, preincubation with anti-Fc receptor antibodies had no effect on uptake, consistent with the absence of $\mathrm{Fc}$ receptor expression on the cardiocytes. Immunohistologic evaluation of human fetal hearts supported the RT-PCR and FACS data. Specifically, PSR staining was evident in the conduction tissue as well as the atria and ventricles of a fetal heart obtained from an electively terminated pregnancy ( 24 weeks gestational age) and the heart from a fetus that died of CHB. In contrast, CD32 was not observed in the healthy heart, but only in the CHB heart, consistent with macrophage infiltration, as previously reported (5).

Anti-SSA/Ro and -SSB/La antibodies inbibit clearance, resulting in accumulation of apoptotic cells. Given the exaggerated apoptosis previously observed in histologic sections of hearts from fetuses dying with $\mathrm{CHB}$, experiments were designed to address the hypothesis that surface SSA/Ro-SSB/La might function as endogenous ligands that promote engulfment of apoptotic cells analogous to annexin I (27). Binding of cognate antibodies to these putative apoptotic cell ligands would be predicted to inhibit this process. Apoptotic cells were prepared by preincubating cardiocytes with TNF- $\alpha$ plus pHEMA (as described above) and then monoclonal antibodies against Ro52, Ro60, and La. Opsonized apoptotic cells were cocultured with proliferating human fetal cardiocytes for 5 hours, extensively washed to remove unbound apoptotic cells, and fixed. Engulfment was assessed after double labeling with TUNEL and anti-FITC-conjugated peroxidase. Engulfment was scored by light microscopy. Preincubation of apoptotic cells with 60.4 (nonopsonized, no antibody binds to apoptotic cells; Table 1) had no effect on engulfment, whereas pretreatment with 60.1 (opsonized) blocked tethering and uptake (reduced from $49.5 \% \pm 8.5 \%$ to $18.6 \% \pm 2.0 \%$; $P=0.016)$. Similarly, opsonization with 52.2 or 48.1 significantly inhibited engulfment to $24.3 \% \pm 4.3 \%(P=0.016$ versus control $)$ and $9.7 \% \pm 7.4 \%(P=0.036$ versus control $)$, respectively. Murine monoclonal antibodies to SSB/La (3B9 and SW3), which bound apoptotic human cardiocytes, also inhibited uptake by proliferating cardiocytes (Table 2). Incubation of apoptotic cells with control antibodies had no effect on the functional assay involving engulfment of apoptotic cells.

Experiments were then performed with apoptotic cardiocytes preincubated with IgG fractions isolated from the sera of women with antibodies to SSA/Ro-SSB/La who have had children with CHB (CHB-IgG). These treated cells were then cocultured with proliferating human fetal cardiocytes for 5 hours and extensively washed. Pretreatment of apoptotic cells with CHB-IgG inhibited tethering and uptake such that only minimal TUNEL staining was 
A

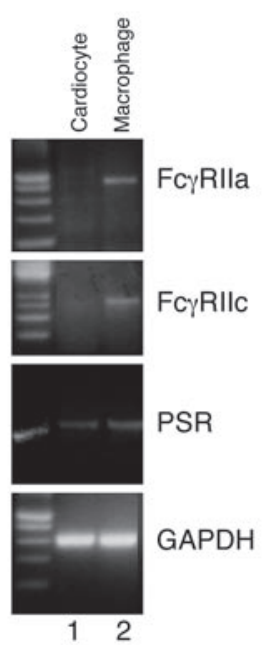

Cardiocyte

anti-PSR

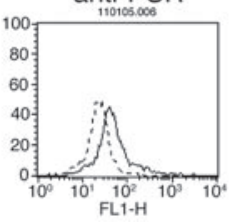
anti-CD32

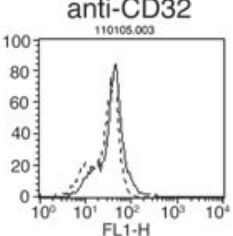

Macrophage anti-CD32

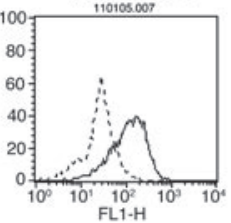

B

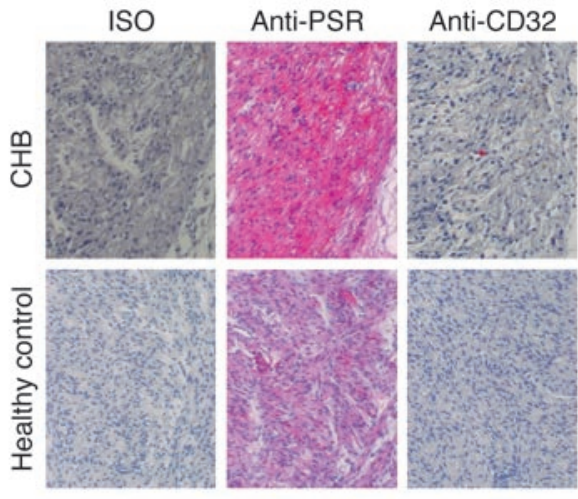

Figure 3

Evidence for expression of PSR and CD32 in human fetal cardiac cells and tissues. (A) Expression of PSR and CD32 (FcyRlla, Fc $\gamma$ RIlc) was assessed by RT-PCR in CDNA (prepared from $\mathrm{mRNA}$ ) isolated from human fetal cardiac cells or from macrophages (left panels). In addition, cells were stained with a specific antibody (solid line) and isotype control (dashed line) for FACS analysis (right panels). (B) Shown are longitudinal sections of septal tissue from a 22-week CHB fetus and from a normal fetus electively terminated at 24 weeks, stained with anti-PSR, with antiCD32, and with isotype control. For all immunostains, stain was visualized with alkaline phosphatase and counterstained with hematoxylin (magnification, $\times 40$ ). observed (Figure 4A). In contrast, preincubation of apoptotic cells with IgG control (nonopsonized) had no effect on engulfment, as extensive TUNEL-peroxidase staining was seen in the cocultured proliferating cardiocytes (Figure 4A). Evaluation of IgG fractions from $8 \mathrm{CHB}$ mothers revealed a negative correlation between the binding of antibody to the apoptotic cells and engulfment by proliferating human fetal cardiocytes $(r=0.81 ; P=0.03)$ (Figure 4B).

In the next evaluation - for cardiocytes preincubated with IgG from a CHB mother and with normal control IgG, after coculture with proliferating cardiocytes - total cells were isolated and stained with annexin $\mathrm{V}$ (no washing step, no permeabilization). The rationale was that the scope should include an analysis of tethered cells as well as nontethered apoptotic cells within the cocultured cells. As indicated by FACS, nonopsonized (normal control IgG) annexin $\mathrm{V}$-positive cells were efficiently engulfed, while opsonized (CHB-1; CHB mother IgG) annexin $\mathrm{V}$-positive cells persisted (representative experiment, Figure $5 ; n=3$ ).

Incubation of apoptotic cells with control antibodies had no effect on the functional assay involving engulfment of apoptotic cells. Specifically, cotreatment of apoptotic cardiac cells with IgG fractions from 2 SLE patients (autoimmune without anti-

\section{Figure 4}

Binding of antibody from IgG fractions of CHB mothers to apoptotic cardiocytes inversely correlates with cardiocyte activity as measured in a functional assay that evaluates the clearance of apoptotic cells by neighboring cells in the presence of these IgG fractions. Apoptotic cardiocytes were treated with healthy control IgG (nonopsonized) or with IgG from an anti-SSA/Ro- and -SSB/La-positive CHB mother (CHB-1; opsonized) as well as 6 additional IgG fractions (from CHB mothers). Each apoptotic cell preparation was subjected to FACS analysis to examine the percentage of human IgG binding. In addition, monolayer cardiocytes were incubated alone, with opsonized apoptotic cells, and with nonopsonized apoptotic cells. After 5 hours, cells were fixed and stained using TUNEL-peroxidase.
SSA/Ro and -SSB/La antibodies but with either ANA [ANA-1] or anti-U1RNP [RNP-1] antibodies) had no effect on engulfment (Table 2). To address the specificity of the relationship between antibody binding and inhibition of uptake, anti-HLA class I was evaluated (Table 1). Despite binding to apoptotic cardiocytes, this antibody had no effect on the clearance of dying cells by neighboring cardiocytes (Table 2).

Assessment of apoptotic binding and inbibition of engulfment in a murine system. To further address the accessibility of $60-\mathrm{kDa}$ SSA/Ro to maternal autoantibodies and its involvement in apoptotic clearance, a series of experiments was performed exploiting the recently described Ro60 murine knockout model (28). Initial studies dem-

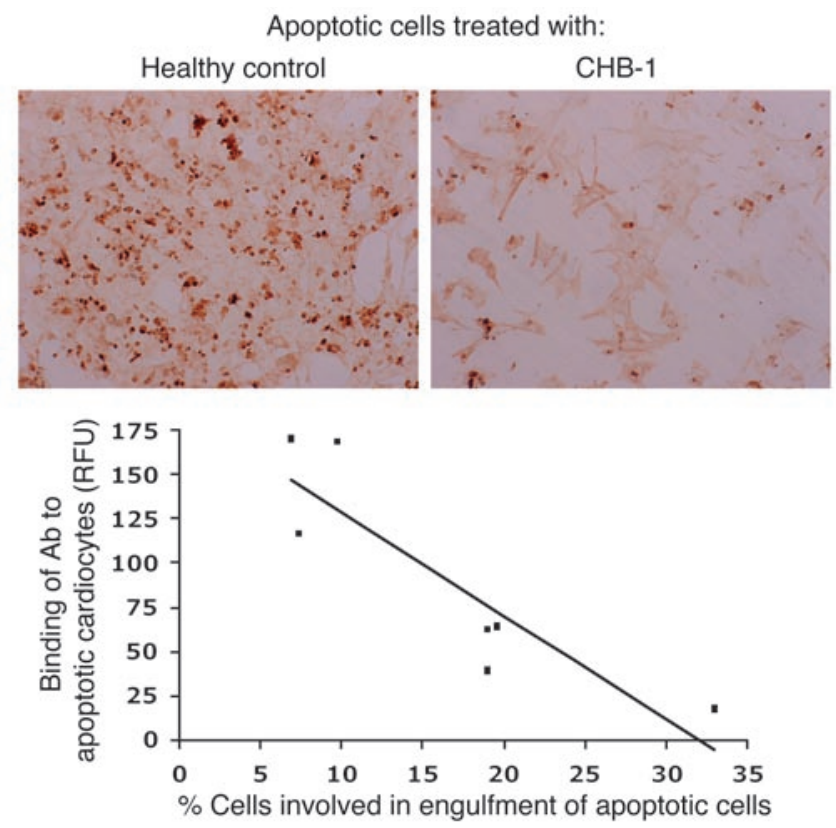



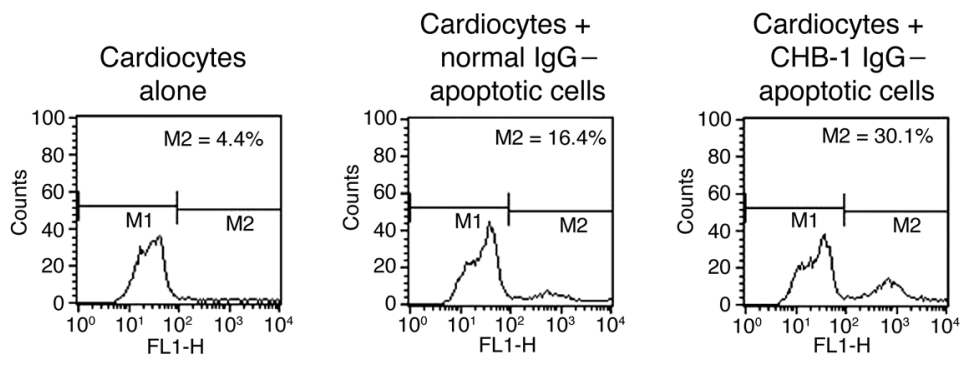

\section{Figure 5}

Use of annexin $V$ to assess the persistence of opsonized and nonopsonized apoptotic cardiocytes after incubation with proliferating cardiocytes (5 hours). Apoptotic cardiocytes were treated with normal control IgG (nonopsonized) or with IgG from an anti-SSA/Ro- and -SSB/La-positive CHB mother (CHB-1; opsonized). Monolayer proliferating cardiocytes were incubated alone, with opsonized apoptotic cells (CHB-1 IgG-apoptotic cells), and with nonopsonized apoptotic cells (normal IgG-apoptotic cells). After 5 hours, cells were scraped from the culture dish and stained using annexin V. M1 and M2 indicate gates of FACS analysis.

onstrated that affinity-purified human anti-Ro60 and anti-La48 antibodies as well as ScFv 60.1 and 48.1 stained digitonin-permeabilized splenocytes isolated from wild-type mice (data not shown). As expected, only the anti-La48 antibodies were reactive with permeabilized splenocytes from the Ro60-knockout mice (Figure 6A). Not surprisingly, given the decreased sequence homology between human and murine Ro52 (29), affinity-purified anti-Ro52 and ScFv 52.2 did not bind to permeabilized wild-type or Ro60-knockout splenocytes (data not shown). None of the antibody preparations bound nonpermeabilized cells (data not shown).

Having established the appropriate reactivities with the human reagents and monoclonal antibodies, murine Ro60-knockout and wild-type cardiocytes were isolated and separately cultured under standard conditions or plated on pHEMA with $10 \mathrm{ng} / \mathrm{ml} \mathrm{TNF-} \alpha$ for 18 hours at $37^{\circ} \mathrm{C}$. Apoptotic cardiocytes were added to healthy cardiocytes, and TUNEL-positive cells were evaluated as described above for Table 2. Affinity-purified anti-La48 but not affinity-puri- fied anti-Ro60 blocked engulfment of the Ro60-knockout apoptotic cardiocytes (Figure 6B), while both antibodies inhibited engulfment of wild-type cardiac cells (data not shown).

\section{Discussion}

In elucidating the pathogenesis of $\mathrm{CHB}$, one of the biologic stumbling blocks has been the intracellular localization of the putative antigen targets. Although it is logical to hypothesize that the target is a cardiac surface protein containing a cross-reactive epitope recognized by anti-SSA/Ro and/or SSB/La antibodies, supportive data are not definitive. Antibodies to the 5HT4 serotoninergic receptors were only rarely present in sera from affected children (30), and the molecular mechanism explaining inhibition of calcium fluxes remains under investigation (31). Recent data on reactivity to the p200 peptide of the $52-\mathrm{kDa}$ SSA/Ro protein and surface binding to intact rat cardiocytes imply that a single pathogenic antibody recognizing p200 may play a key role in CHB (32). Whether this specific reactivity with p200 or an even finer epitope within the p200 region represents cross-reactivity with a distinct cardiac surface antigen or represents reactivity with translocated Ro52 in cells that were actually in the early stages of apoptosis remains unknown. However, a direct pathologic consequence to cells by inhibiting function, as in neonatal myasthenia gravis (33), or type II cytotoxic reactivity, as in hemolytic disease of the newborn (34), would predict a much higher recurrence rate of $\mathrm{CHB}$ in subsequent pregnancies than the observed 18\% (35).

An alternative explanation - consistent with the rarity, spectrum, and unique fetal expression of this disease - considers the role of apoptosis in initiating the link between antibody and subsequent fibrosis of healthy cardiac tissue. Under physiologic circumstances, apoptosis is a distinct form of death in which the cell commits to a suicide program, leading to elimination without inflammation $(36,37)$. The mechanism by which this is accomplished during fetal development of the human heart is not fully defined. In areas of high remodeling such as the conduction system, it might
A
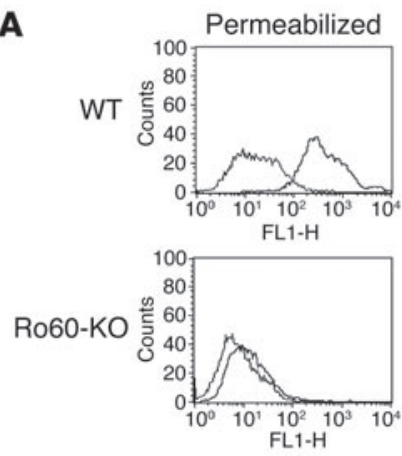

B N/A Healthy $\lg G \quad$ AP48

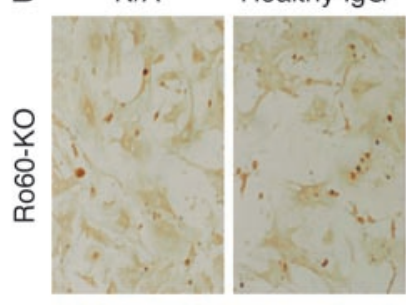

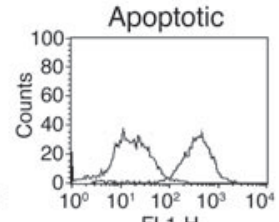

$\mathrm{FL} 1-\mathrm{H}$

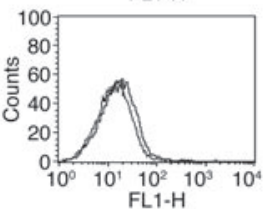

AP52
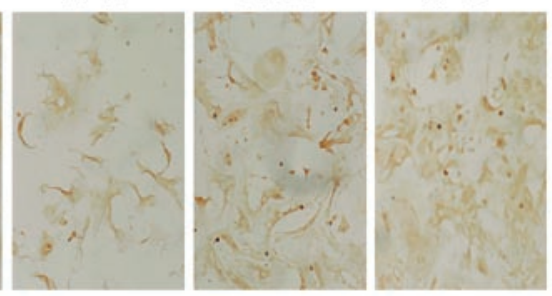
Ro52; and affinity-purified anti-Ro60. 
be advantageous for the organism to enlist adjacent healthy cells as "amateur" phagocytes to more efficiently accomplish clearance. Circumstantial evidence in support of such a mechanism is provided by the absence of macrophages in the septal region of healthy fetal hearts (5). The present study provides the first direct evidence to our knowledge that cultured healthy human fetal cardiocytes can remove apoptotic cells. While the specific cardiac surface receptors that recognize and engage the adjacent apoptotic cells are not known, PSRs were expressed on human fetal cardiocytes. Inhibition of apoptotic cell uptake by antibody blocking of the PSR supports a functional role for these receptors in this process. Precedent for these findings is the recent demonstration by Monks et al. that mammary epithelial cells absent classic Fc receptors engulf apoptotic cells via engagement of the PSR (38).

Signals presented from apoptotic cells may induce a variety of responses in engulfing cells, which are likely mediated by a number of cell-surface ligands to coordinate the precise sequence of events associated with engulfment. Experiments presented herein support the hypothesis that antigens of the SSA/Ro-SSB/La RNP complex may be previously undescribed ligands on the apoptotic cell. Surface exposure of these antigens is a consequence of intracellular caspase activation in apoptotic cells common to both the extrinsic and intrinsic pathways. Monoclonal antibodies and IgG fractions containing antibodies against SSA/Ro-SSB/La inhibit uptake of apoptotic cells by the healthy cardiocytes. This inhibition suggests that engagement of translocated SSA/Ro-SSB/La antigens with receptors on engulfing cells initiates a signal that mediates tethering and internalization. To date, the putative receptor on engulfing cells for SSA/Ro-SSB/La has not been identified. One speculation is that these autoantigens associate with known co-ligands such as PS on the cell membrane, analogous to annexin I (27). Alternatively, opsonization of apoptotic cells may sterically hinder the interaction between PS and PSR or other receptor/ligand pairs.

Gandhi and colleagues report that a human monoclonal antibody polyreactive with Ro52 and Ro60, which bound late-stage apoptotic but not healthy MOLT-4 cells, significantly diminished the phagocytosis of these cells by activated THP-1 cells (39). Since the antibody employed was IgM, this would explain the absence of uptake via Fc receptor as reported in our previous studies of maternal IgG anti-Ro/La-opsonized apoptotic cardiocytes cocultured with macrophages (40). Thus, the results by Gandhi et al. mimic the effect of our coculturing experiments with autologous fetal cardiocytes, in that anti-SSA/Ro antibodies block phagocytosis.

Given the role of the cardiocyte in the physiologic removal of apoptotic cells, perturbation of this developmental function by circulating maternal anti-SSA/Ro and -SSB/La antibodies could account for the exaggerated apoptosis consistently observed in the $\mathrm{CHB}$ hearts. Indeed, high levels of expression of Fas and FADD, key components in the apoptotic machinery, were observed in CHB hearts compared with healthy controls (R.M. Clancy, unpublished observation), further supporting the presence of exaggerated apoptosis in CHB hearts. Blocking physiologic apoptotic cell removal by inadvertent autoantibody binding of apoptotic cells would be expected to skew the pool of IgG-apoptotic cell complexes toward proinflammatory clearance by infiltrating macrophages. Of relevance to this proposed model of injury, human fetal cardiocytes did not express classic Fc receptors, and antibodies reactive with $\mathrm{Fc}$ did not influence apoptotic uptake by nonopsonized cardiocytes. This further implies that, unlike macrophages, cardiocytes are not capable of diverting apoptotic clearance toward an inflammatory pathway. The inflammatory consequences of uptake via macrophage Fc receptors may lead to fibrosis and permanent heart block. This scenario is supported by previous data demonstrating that supernatants from macrophages cocultured with opsonized apoptotic human fetal cardiocytes transdifferentiate cardiac fibroblasts to myofibroblasts, a scarring phenotype (40). Prolonged secretion of cytokines such as TGF- $\beta$ may contribute to the exuberant scarring seen in CHB (41).

A recent report by Kuhn and colleagues provides further evidence in support of a role for SSA/Ro-SSB/La antigens in apoptotic clearance (42). In tissue sections from patients with cutaneous lupus erythematosus (several of whom had anti-SSA/Ro and -SSB/La antibodies), the level of epidermal apoptotic cells was significantly increased 72 hours after UV irradiation compared with 24 hours, while the level of apoptotic cells decreased in control subjects over this same time frame. Similar findings have been described in a murine Ro60-knockout model (28). Specifically, in mice devoid of Ro60, UVB irradiation resulted in significantly increased numbers of apoptotic keratinocytes compared with wild-type mice. One interpretation of these human and murine data is that Ro60 is involved in cell survival, and thus increased apoptosis is a reflection of the loss of survival signals, with the net effect being exaggerated apoptosis. While this interpretation is sound in the murine model, it would be plausible in the cutaneous lupus patients only if the autoantibodies penetrated cells to simulate a murine knockout. However, an alternative explanation, consistent with the results presented in our studies utilizing human and murine cells, is that the increased numbers of keratinocytes present after photoprovocation represent a defect in clearance of these cells, because either anti-Ro60 antibodies inhibit phagocytic uptake or the Ro60 ligand for uptake is absent.

The key observation of this study is that human fetal cardiocytes are capable of engulfing apoptotic cardiocytes and that autoantigens serve as a natural ligand in this process. It is apparent that SSA/Ro$\mathrm{SSB} / \mathrm{La}$ can have dual functions depending on whether they are intracellular proteins in live cells or translocated to the surface of apoptotic cells. The findings presented herein are based primarily on in vitro findings, and further studies are needed to unambiguously establish that this mechanism is operative in vivo. Mapping "apotopes" (epitopes expressed on apoptotic cells) recognized by the different $\mathrm{ScFv}$ antibodies in order to identify domains on the SSA/Ro-SSB/La antigens that mediate clearance and identifying the counter-receptor(s) are important future directions. Inhibition of physiologic clearance by maternal autoantibodies at a time of intense remodeling of the human conduction system would be expected to have serious consequences. Antibodies to SSA/Ro and SSB/La divert clearance of apoptotic cells toward macrophage uptake, with consequent inflammation and scarring. Positing apoptosis as the critical link between antibodies and eventual scarring of the atrioventricular node is consistent with many of the clinical observations, including rarity of disease, relatively low recurrence rates, discordance in monozygotic twins, and unique fetal (as opposed to maternal) vulnerability (1). While steps beyond apoptosis may dictate the spectrum of conduction abnormalities, focus on identification of the trigger for physiologic apoptosis and the circuitry explaining exaggerated apoptosis should be a priority.

\section{Methods}

Cultured human fetal cardiocytes and murine wild-type and Ro60-knockout splenocytes and cardiocytes. Human fetal cardiocytes of gestational age 16-24 weeks 
were aseptically obtained after elective termination of normal pregnancy in accordance with the guidelines of the Institutional Review Board of New York University School of Medicine and after obtaining consent from the mothers, and were cultured as described (43). By day 4 in culture, spontaneous contraction (>30 bpm) was observed under phase-contrast microscopy. More than $75 \%$ of the cells were stained by a murine monoclonal anti$\alpha$-sarcomeric actinin antibody, which stains $Z$ lines and dots in stress fibers of skeletal and cardiac muscle but not in nonsarcomeric muscle elements such as connective tissue, epithelium, nerves, or smooth muscle (4).

Murine splenocytes were isolated by mechanical disruption from spleens obtained after dissection of C57BL/6 mice (wild-type or Ro60-knockout; generous gift of Sandra Wolin, Yale University, New Haven, Connecticut, USA). Wild-type and Ro60-knockout splenocytes were cultured in RPMI plus $10 \%$ fetal calf serum, $1 \mathrm{mM} 2$-mercaptoethanol. Murine wild-type and Ro60-knockout cardiocytes were isolated by enzymatic digestion and cultured in DMEM plus 10\% fetal calf serum. All animal studies were approved by the Institutional Animal Care and Use Committee of New York University School of Medicine.

Activation of apoptotic pathway in buman fetal cardiocytes. Human fetal cardiocytes were treated with IFN- $\gamma(1 \mu \mathrm{g} / \mathrm{ml}, 24$ hours; Sigma-Aldrich $)$ and then given apoptotic stimuli: anti-CD95 IgM (100 ng/ml; Upstate USA Inc.; clone no. CH11) or TNF- $\alpha(5 \mathrm{ng} / \mathrm{ml}$; Invitrogen $)$ in the presence of cycloheximide $(1 \mu \mathrm{g} / \mathrm{ml}$; Sigma-Aldrich) and IFN- $\gamma(1 \mu \mathrm{g} / \mathrm{ml})$ on tissue culture dishes coated with pHEMA (Sigma-Aldrich P3932) $(26,40)$ at $37^{\circ} \mathrm{C}$ (time varied). The use of pHEMA to induce apoptosis was previously described by our group $(26,40)$. For experiments involving pretreatment of cardiocytes with Z-VAD-FMK, cardiocytes were cotreated with TNF- $\alpha$ and Z-VAD-FMK $(1 \mu \mathrm{M}$; Promega). Apoptosis was assessed using 2 methods: staining with annexin $V$ (to detect PS) and with anti-active caspase-3. Briefly, annexin V was used to stain proliferating and apoptotic cardiocytes as recommended by the manufacturer (no. 556419; BD Biosciences - Pharmingen). The annexin stains included proliferating cardiocytes, apoptotic preparations, and a mixture of healthy control and apoptotic cells at 5 hours after treatment. Prior to FACScan analysis, cells were permeabilized with digitonin (no. 51-2090KZ; BD Biosciences) to permit evaluation of active caspase-3 (APO ACTIVE Antibody Caspase-3; Cell Technology Inc.).

Preparation of anti-SSA/Ro and -SSB/La and pooled IgG antibodies from bealthy controls and patients. Recombinant human 48-kDa SSB/La, 52-kDa SSA/ Ro-kDa, and 60-kDa SSA/Ro were obtained using E. coli-transformed cells with the appropriate plasmids. Proteins were purified to homogeneity as described previously $(15,44)$. Using a Protein A-IgG isolation kit (no. 20356; Pierce Biotechnology), human IgG was isolated using serum from a healthy control as well as a mother whose serum contains antibodies to all components of the SSA/Ro-SSB/La complex and whose child had CHB. Protein concentrations of affinity-purified antibodies and IgG fractions were assessed using a protein quantification kit (Pierce Biotechnology).

Preparation of monoclonal anti-SSA/Ro and -SSB/La antibodies. Female chickens were immunized either with a mixture of recombinant human $48-\mathrm{kDa}$ $\mathrm{SSB} / \mathrm{La}$ and 52-kDa SSA/Ro or with human fetal cardiocytes rendered apoptotic by treatment with staurosporine (4) at a commercial laboratory (Pocono Rabbit Farm and Laboratory Inc.). For the former immunization, $50 \mu \mathrm{g}$ of recombinant protein in CFA was injected intramuscularly. The first 2 boosters were given at 7 - to 10-day intervals using $25 \mu$ g of recombinant protein in incomplete Freund's adjuvant. Booster injections were continued with a similar regularity until primary responses were detected. For the latter immunization, a chicken was immunized with $10^{7}$ human fetal apoptotic cardiocytes (no adjuvant). Boosters were given at the same interval as described with immunization using recombinant protein (minus adjuvant). After an antibody response was achieved, the bone marrow B cells were obtained. A pComb3X library was constructed for each chicken. Briefly, adapting a standard protocol (45), avian bone marrow and spleen were separately harvested into serum-free RPMI, dissociated into single-cell mononuclear cell suspensions, and then lysed in TRIzOL (Invitrogen). An antibody library was constructed using PCR amplifications of the single $\mathrm{VH}$ and $\mathrm{VL}$ genes in separate reactions for the $2 \mathrm{immu}-$ nizations, and a pComb3X library was constructed (pComb3X, kind gift of Carlos Barbas III, The Scripps Research Institute, La Jolla, California, USA). Panning for the anti-SSA/Ro and -SSB/La and antiapoptotic libraries was performed separately. Each employed a screen against wells containing each recombinant protein (Ro60, Ro52, and La48). Briefly, wells were coated overnight with $0.1-0.2 \mu \mathrm{g}$ of recombinant protein in PBS, washed with PBS containing 0.05\% Tween-20 (PBS-Tween), blocked with $3 \%$ BSA/PBS-Tween, washed with PBS-Tween, and incubated with phage in PBS-albumin. For each library, 2 rounds of panning were performed, each using $2 \times 10^{12}$ phage from a chicken lymphocyte antibody library with a complexity of $4 \times 10^{7}$. Eleven monoclonal antibodies were isolated. Each clone was unique based on the variations in Bst01 recognition site patterns due to DNA sequence differences (data not shown).

The clone was placed in a host that manufactures a soluble ScFv, and these monoclonal antibodies were analyzed using ELISA and Western blot methods with recombinant SSA/Ro-SSB/La antigen (i.e., Ro60, Ro52, and La48; ELISA) and a MOLT-4 lysate (Western blotting) $(46,47)$ as the target antigens. $\mathrm{ScFv}$ binding required the use of anti-HA probe (Chemicon International) and the use of anti-mouse alkaline phosphatase or anti-mouse peroxidase as tertiary antibodies for ELISA and Western blotting, respectively.

The ScFv anti-60 (m60.1, m60.2, m60.3, m60.4, m60.5) antibodies reacted strongly to recombinant Ro60 but not Ro52 or La48 (ELISA; data not shown). These ScFv anti-60 antibodies were incubated on strips containing separated MOLT-4 protein, and antibody reactivity was observed at Ro60, confirming the reactivity in the ELISA (data not shown). ScFv anti-52 (m52.1, m52.2, m52.3, m52.4) and ScFv anti-48 (m48.1, m48.2) were selectively reactive against Ro52 and La48, respectively, according to ELISA (data not shown).

For surface plasmon resonance imaging, recombinant SSA/Ro60 was covalently attached to the sensor chip of the Biacore 3000 instrument (Biacore) (1,000 molecules per chip). Varied concentrations of ScFv anti60 antibodies were introduced into the flow chamber. Resonance, a realtime parameter that reflects the dynamic nature of the binding system, is recorded versus time. A sequential measurement of association and dissociation was obtained using varied concentrations of monoclonal antibody. The concentrations used were $500 \mathrm{nM}, 250 \mathrm{nM}, 125 \mathrm{nM}, 62.7 \mathrm{nM}$, and $31.3 \mathrm{nM}$. Each concentration, with a separate analysis in duplicate, was introduced to the chip via a microinjection. The data for 60.1 and 60.4 (reported as the surface plasmon resonance signal versus time) are shown in Figure 1. Values for $K_{\mathrm{a}}$ and $K_{\mathrm{d}}$ were derived using the experimentally determined $K+1$ and $K-1$ (rate constants of the forward and reverse reactions, respectively).

Staining of human fetal cardiocytes. ScFv monoclonal antibodies were a valuable immunological tool to evaluate SSA-Ro/SSB-La expression by nonpermeabilized proliferating cardiocytes, permeabilized proliferating cardiocytes, and nonpermeabilized apoptotic cardiocytes. In these stains, there was the sequential use of primary antibody ( $\mathrm{ScFv}$ monoclonals; $15 \mu \mathrm{g} / \mathrm{ml}$ ), secondary antibody (anti-HA tag; Chemicon International) $(1: 3,000)$, and tertiary antibody (goat anti-mouse FITC; Sigma-Aldrich) (1:3,000). For permeabilization of cells, digitonin was used, and antibodies were diluted in a digitonin-containing solution using a kit as recommended by the manufacturer (BD Cytofix/Cytoperm Kit; BD Biosciences).

The double-staining regimen involved the sequential use of primary antibody (ScFv monoclonals; $15 \mu \mathrm{g} / \mathrm{ml}$ ), secondary antibody (anti-HA tag; Chemicon International) $(1: 3,000)$, and tertiary antibody (a mixture of goat 
anti-mouse PE [no. 1032-09, SouthernBiotech], 1:3,000, and Annexin V: FITC [no. 556419, BD Pharmingen], 1:50). Annexin is widely used to determine cell death that occurs via necrosis and apoptosis (48). In addition, necrosis was monitored according to LDH leakage, which was measured using a commercial kit (228; Sigma-Aldrich).

PSR, Fc RII expression in cardiocytes. Total RNA was isolated from the cells by homogenizing the cell pellets in TRIzOL (Invitrogen) reagent for $1 \mathrm{~min}$ ute. RNA was extracted by chloroform treatment and propanol precipitation. Total RNA $(5 \mu \mathrm{g})$ was reverse transcribed from an oligo(dT) primer in a $20 \mu \mathrm{l}$ final reaction volume, and SuperScript Transcriptase (Invitrogen) was used according to the manufacturer's recommendations. For PCR reactions, $2 \mu$ l of the cDNA from each RT reaction was amplified with the gene-specific primers in $50 \mu \mathrm{l}$ volume containing $5 \%$ formamide and Vent Polymerase (New England Biolabs Inc.). The PCR reactions were subjected to $20,25,30$, and 35 cycles with denaturation at $98^{\circ} \mathrm{C}$ for 40 seconds, reannealing at $50^{\circ} \mathrm{C}$ for 1 minute, extension of $67^{\circ} \mathrm{C}$ for 1 minute. The PCR products were analyzed by electrophoresis through a $1 \%$ agarose gel stained with ethidium bromide. PSR was amplified by RT-PCR using the specific primers designed from the published sequences. Primers for PSR were PSRF, 5'-GACTCTGGAGCGCCTAAAAA-3', and PSRR, 5'-CCCTGAACTAAGGCATTCCA-3' (49).

Primers for Fc $\gamma$ RIIa were: Fc $\gamma$ RIIaF, 5'-CAGCATGGGCAGCTCTTC3'; FcyRIIaR, 5'-CACATGGCATAACGTTAC-3'; Fc $\gamma$ RIIcF, 5'-CTCCCAGCTCTTCACCGA-3'; and Fc ${ }^{\prime}$ RIIcR, 5'-CACATGGCATAACGTTAC-3' (50). In addition, cardiocytes were stained with anti-PSR (Sigma-Aldrich) and with anti-CD32 (BD Biosciences - Pharmingen) and appropriate FITC-conjugated antibodies, followed by FACS analysis.

Immunohistochemistry of human fetal heart sections. Formalin-fixed paraffin sections were obtained from a heart of a fetus from an electively terminated pregnancy at 24 weeks and a heart from a 22-week fetus that died of CHB. The clinical description and gross anatomy of the CHB heart has been previously described (5). Sections of fetal heart were immunostained as described (5). Briefly, anti-PSR (Sigma-Aldrich), anti-CD32 (BD Biosciences), mouse control IgG (Accurate), or rabbit control IgG (Accurate) were used as primary antibodies, and anti-rabbit IgG alkaline phosphatase or anti-mouse IgG alkaline phosphatase were secondary antibodies. Sections were visualized and counterstained before photography.

Engulfment assay. Cardiocytes were treated to induce apoptosis by plating on tissue culture dishes coated with pHEMA plus TNF- $\alpha(5 \mathrm{ng} / \mathrm{ml})$ for 18 hours at $37^{\circ} \mathrm{C}$. Apoptotic cells were treated with varied $\operatorname{IgG}(0.3 \mathrm{mg} / \mathrm{ml}$, 30 minutes). Then, $3 \times 10^{6}$ to $5 \times 10^{6}$ cells from the apoptotic population were added in a total volume of $1 \mathrm{ml}$ of DMEM plus $10 \%$ FCS to individual antibody preparations, which included: ScFv monoclonal antibodies $(15 \mu \mathrm{g} / \mathrm{ml}) ;$ IgG fractions from an anti-SSA/Ro- and -SSB/La-positive mother of a child with CHB $(0.3 \mathrm{mg} / \mathrm{ml})$; IgG fraction from a healthy control $(0.3 \mathrm{mg} / \mathrm{ml})$; IgG derived from a patient with SLE who was ANA positive, SSA/Ro-SSB/La negative $(0.3 \mathrm{mg} / \mathrm{ml})$; monoclonal antibodies 3B9 (reactive with the hLaA subfragment; $50 \mu \mathrm{g} / \mathrm{ml}$; a gift from Michael Bachmann, Oklahoma Medical Research Foundation, Oklahoma City, Oklahoma, USA), SW3 (reactive with the hLaC subfragment; $50 \mu \mathrm{g} / \mathrm{ml}$ ), Sal-5 (isotype control, $50 \mu \mathrm{g} / \mathrm{ml})$, and anti-CD32 $(10 \mu \mathrm{g} / \mathrm{ml}$; BD Biosciences - Pharmingen). These apoptotic cell preparations were added to proliferating cardiocytes (described below) or directly stained with the appropriate secondary or tertiary antibodies and then analyzed by FACScan.

In one set of experiments, anti-PSR antibody $(100 \mu \mathrm{g} / \mathrm{ml}$; SigmaAldrich) or anti-HLA class I antibody (10 $\mu \mathrm{g} / \mathrm{ml}$; Sigma-Aldrich) or rabbit IgG was added to healthy cardiocytes prior to the cotreatment with nonopsonized apoptotic cardiocytes.

Prior to cotreatment of apoptotic cells, 1,000 separately cultured, otherwise healthy cardiocytes were plated on glass coverslips. Then, individual preparations of apoptotic cardiocytes were added to these healthy cardiocytes (2:1 ratio, 5 hours). Viable and apoptotic cells were incubated for 5 hours or 18 hours, followed by washing to remove nonadherent apoptotic cells. The remaining apoptotic cells, which were tethered to intact cardiocytes, were treated with TUNEL reagents (Roche Diagnostics) to aid in their identification. Cell preparations were analyzed after staining using a secondary peroxidase-labeled antibody (also included in the TUNEL kit). Engulfment was scored using a light microscope by an investigator without knowledge of treatments. For each stain, 100 cells were examined in each duplicate well, and the number of cells that stained positive were then averaged. A cell was considered positive for engulfment if it was bound by or had internalized a TUNEL-positive cell. It is acknowledged that this method may underestimate uptake. In many instances, healthy cardiocytes have taken up multiple TUNEL-positive particles; however, it is not presently possible to distinguish a healthy cell that has taken up multiple apoptotic bodies from a healthy cell that has broken down one apoptotic body into multiple breakdown bodies. A similar technique for enumerating apoptotic uptake by mammalian epithelial cells has been recently reported by Monks et al. (38). The percentage of cells involved in engulfment of apoptotic cells was determined by dividing the number of cells with bound apoptotic cells by the total number of cells.

In select experiments, the cardiocyte preparation was stained with anti$\alpha$-sarcomeric actinin and a Cy3-labeled secondary antibody. A scanning laser confocal microscope system (Bio-Rad confocal microscope; MRC1024 , Zeiss) was used to determine the cellular localization of the TUNELlabeled cells, which were within the neighboring cardiac cells. Scanning the specimens either sequentially or simultaneously using the 3 excitation lines in the krypton-argon laser gave good separation of the 3 image planes. Each figure was generated by projecting the stack of images onto a single plane.

Statistics. The Mann-Whitney $U$ test was used to compare FACS mean fluorescent measurements between the different groups. Linear regression analysis was performed in the analysis of the binding of patient IgG to apoptotic cells and its effect on engulfment by cardiocytes. $P<0.05$ was considered statistically significant.

\section{Acknowledgments}

This work was supported by NIH grant AR-42455 to J.P. Buyon and grants from March of Dimes Birth Defects Foundation (1-FY03-91) and Sjögren's Syndrome Foundation to R.M. Clancy. We acknowledge training and technical support of Gregg Silverman, the UCSD Rheumatic Diseases Core Center (NIH grant P30 AR47360), and the Cold Springs Harbor Laboratory course on phage display of combinatorial libraries. Patient materials and data were provided by the Research Registry for Neonatal Lupus (supported by National Institute of Arthritis and Musculoskeletal and Skin Diseases contract no. AR-4-2271 to J.P. Buyon). We thank Lily Lavner and Sean Bennett, who provided technical assistance in the preparation of the antibody phage library; Sandra Wolin, who provided the C57BL/6 Ro60-knockout mice; Michael Bachmann, who provided monoclonal antibody 3B9; and Carlos Barbas III, who provided $\mathrm{pComb3X}$.

Received for publication December 29, 2005, and accepted in revised form June 13, 2006.

Address correspondence to: Robert M. Clancy, Department of Medicine, Division of Rheumatology, New York University School of Medicine, 560 First Avenue, TH-407, New York, New York 10016, USA. Phone: (212) 263-0745; Fax: (212) 263-0759; E-mail: bobdclancy@aol.com. 
1. Buyon, J.P. 2004. Neonatal lupus syndrome. In Systemic lupus erythematosus. 4th edition. R.G. Lahita editor. Elsevier Academic Press. San Diego, California, USA. 449-484.

2. Buyon, J.P., and Clancy, R.M. 2003. Maternal autoantibodies and congenital heart block: mediators, markers, and therapeutic approach. Semin. Arthritis Rheum. 33:140-154.

3. Casciola-Rosen, L.A., Anhalt, G., and Rosen, A. 1994. Autoantigens targeted in systemic lupus erythematosus are clustered in two populations of surface structures on apoptotic keratinocytes. J. Exp. Med. 179:1317-1330.

4. Miranda, M.E., et al. 1998. Accessibility of SSA/Ro and SSB/La antigens to maternal autoantibodies in apoptotic human fetal cardiac myocytes. J. Immunol. 161:5061-5069.

5. Clancy, R.M., Kapur, R.P., Molad, Y., Askanase, A.D., and Buyon, J.P. 2004. Immunohistologic evidence supports apoptosis, IgG deposition, and novel macrophage/fibroblast crosstalk in the pathologic cascade leading to congenital heart block. Arthritis Rheum. 50:173-182.

6. Tran, H.B., et al. 2002. Anti-La/SSB antibodies transported across the placenta bind apoptotic cells in fetal organs targeted in neonatal lupus. Arthritis Rheum. 46:1572-1579.

7. Tran, H.B., et al. 2002. Subcellular redistribution of la/SSB autoantigen during physiologic apoptosis in the fetal mouse heart and conduction system: a clue to the pathogenesis of congenital heart block. Arthritis Rheum. 46:202-208.

8. Tran, H.B., Cavill, D., Buyon, J.P., and Gordon, T.P 2004. Intravenous immunoglobulin and placental transport of anti-Ro/La antibodies: comment on the letter by Kaaja and Julkunen. Arthritis Rheum. 50:337-338

9. Chinnaiyan, A.M., O’Rourke, K., Tewari, M., and Dixit, V.M. 1995. FADD, a novel death domain-containing protein, interacts with the death domain of Fas and initiates apoptosis. Cell. 81:505-512.

10. Hsu, H., Xiong, J., and Goeddel, D.V. 1995. The TNF receptor 1 -associated protein TRADD signals cell death and NF-kappa B activation. Cell. 81:495-504.

11. Boldin, M.P., Goncharov, T.M., Goltsev, Y.V., and Wallach, D. 1996. Involvement of MACH, a novel MORT1/FADD-interacting protease, in Fas/ APO-1- and TNF receptor-induced cell death. Cell. 85:803-815

12. Muzio, M., et al. 1996. FLICE, a novel FADDhomologous ICE/CED-3-like protease, is recruited to the CD95 (Fas/APO-1) death-inducing signaling complex. Cell. 85:817-827.

13. Hirata, H., et al. 1998. Caspases are activated in a branched protease cascade and control distinct downstream processes in Fas-induced apoptosis. J. Exp. Med. 187:587-600.

14. Slee, E.A., et al. 1999. Ordering the cytochrome cinitiated caspase cascade: hierarchical activation of caspases-2, -3, -6, -7, -8, and -10 in a caspase-9dependent manner. J. Cell Biol. 144:281-292.

15. Miranda-Carus, M.E., et al. 2000. Anti-SSA/Ro and anti-SSB/La autoantibodies bind the surface of apoptotic fetal cardiocytes and promote secretion of TNF-alpha by macrophages. J. Immunol. 165:5345-5351.

16. Clancy, R.M., Chan, E.K., Chandrashekhar, S., and Buyon, J.P. 2003. Does the cellular localization of antigens in or on apoptotic blebs influence the pathogenicity or benefit of cognate antibodies? Comment on the article by Dieude et al. [letter]. Arthritis Rheum. 48:2080-2082.

17. Savill, J., and Fadok, V. 2000. Corpse clearance defines the meaning of cell death. Nature. 407:784-788.

18. Gregory, C.D. 2000. CD14-dependent clearance of apoptotic cells: relevance to the immune system. Curr. Opin. Immunol. 12:27-34.

19. Fadok, V.A., et al. 2000. A receptor for phosphatidylserine-specific clearance of apoptotic cells. Nature. 405:85-90.

20. Li, M.O., Sarkisian, M.R., Mehal, W.Z., Rakic, P., and Flavell, R.A. 2003. Phosphatidylserine receptor is required for clearance of apoptotic cells. Science. 302:1560-1563.

21. Hanayama, R., et al. 2002. Identification of a factor that links apoptotic cells to phagocytes. Nature. 417:182-187.

22. Sharma, P.R., Anderson, R.H., Copp, A.J., and Henderson, D.J. 2004. Spatiotemporal analysis of programmed cell death during mouse cardiac septation. Anat. Rec. A Discov. Mol. Cell. Evol. Biol. 277:355-369.

23. Wood, W., et al. 2000. Mesenchymal cells engulf and clear apoptotic footplate cells in macrophageless PU.1 null mouse embryos. Development. 127:5245-5252.

24. Henson, P.M., Bratton, D.L., and Fadok, V.A. 2001. Apoptotic cell removal. Curr. Biol. 11:R795-R805.

25. Fadok, V.A., Bratton, D.L., and Henson, P.M. 2001. Phagocyte receptors for apoptotic cells: recognition, uptake, and consequences. J. Clin. Invest. 108:957-962. doi:10.1172/JCI200114122.

26. Neufing, P.J., et al. 2005. Exposure and binding of selected immunodominant $\mathrm{La} / \mathrm{SSB}$ epitopes on human apoptotic cells. Arthritis Rheum. 52:3934-3942

27. Arur, S., et al. 2003. Annexin I is an endogenous ligand that mediates apoptotic cell engulfment. Dev. Cell. 4:587-598.

28. Xue, D., et al. 2003. A lupus-like syndrome develops in mice lacking the Ro 60-kDa protein, a major lupus autoantigen. Proc. Natl. Acad. Sci. U. S. A. 100:7503-7508.

29. Chan, E.K., Hamel, J.C., Peebles, C.L., Buyon, J.P., and Tan, E.M. 1990. Molecular characterization and cloning of the $52 \mathrm{kDa}$ SS-A/Ro protein. $\mathrm{Mol}$. Biol. Rep. 14:53.

30. Buyon, J.P., et al. 2002. Cardiac 5-HT(4) serotoninergic receptors, $52 \mathrm{kD} \mathrm{SSA} /$ Ro and autoimmuneassociated congenital heart block. J. Autoimmun. 19:79-86.

31. Boutjdir, M., et al. 1998. Serum and immunoglobulin $\mathrm{G}$ from the mother of a child with congenital heart block induce conduction abnormalities and inhibit L-type calcium channels in a rat heart model. Pediatr. Res. 44:11-19.

32. Salomonsson, S., et al. 2005. Ro/SSA autoantibodies directly bind cardiomyocytes, disturb calcium homeostasis, and mediate congenital heart block. J. Exp. Med. 201:11-17.

33. Polizzi, A., Ruggieri, M., and Vincent, A. 2001. Pyridostigmine-induced microcephaly. Neurology. 56:1606-1607.

34. Festin, M.R., Limson, G.M., and Maruo, T. 1997. Autoimmune causes of recurrent pregnancy loss. Kobe J. Med. Sci. 43:143-157.

35. Buyon, J.P., et al. 1998. Autoimmune-associated congenital heart block: demographics, mortality, morbidity and recurrence rates obtained from a national neonatal lupus registry. J. Am. Coll. Cardiol. 31:1658-1666.

36. Caricchio, R., Reap, E.A., and Cohen, P.L. 1998. Fas/Fas ligand interactions are involved in ultraviolet-B-induced human lymphocyte apoptosis. J. Immunol. 161:241-251.

37. Fadok, V.A., et al. 1998. Macrophages that have ingested apoptotic cells in vitro inhibit proinflammatory cytokine production through autocrine/ paracrine mechanisms involving TGF- $\beta$, PGE2, and PAF. J. Clin. Invest. 101:890-898.

38. Monks, J., et al. 2005. Epithelial cells as phagocytes: apoptotic epithelial cells are engulfed by mammary alveolar epithelial cells and repress inflammatory mediator release. Cell Death Differ. 12:107-114.

39. Gandhi, R., Hussain, E., Das, J., Handa, R., and Pal, R. 2006. Anti-idiotype-mediated epitope spreading and diminished phagocytosis by a human monoclonal antibody recognizing late-stage apoptotic cells. Cell Death Differ. doi:10.1038/sj.cdd.4401866.

40. Clancy, R.M. et al. 2002. Transdifferentiation of cardiac fibroblasts, a fetal factor in anti-SSA/Ro$\mathrm{SSB} /$ La antibody-mediated congenital heart block. J. Immunol. 169:2156-2163.

41. Clancy, R.M., and Buyon, J.P. 2003. Clearance of apoptotic cells: TGF-beta in the balance between inflammation and fibrosis. J. Leukoc. Biol. 74:959-960.

42. Kuhn, A., et al. 2006. Accumulation of apoptotic cells in the epidermis of patients with cutaneous lupus erythematosus after ultraviolet irradiation. Arthritis Rheum. 54:939-950.

43. Tseng, C.E., et al. 1999. mRNA and protein expression of SSA/Ro and SSB/La in human fetal cardiac myocytes cultured using a novel application of the Langendorff procedure. Pediatr. Res. 45:260-269.

44. Miranda-Carus, M.E., et al. 1998. Induction of antibodies reactive with SSA/Ro-SSB/La and development of congenital heart block in a murine model. J. Immunol. 161:5886-5892.

45. Barbas, C.F., III, Burton, D.R., Scott, J.K., and Silverman, G.J. 2001. Phage display: a laboratory manual. Cold Springs Harbor Laboratory Press. Cold Springs Harbor, New York, USA. 736 pp.

46. Buyon, J.P., Slade, S.G., Reveille, J.D., Hamel, J.C., and Chan, E.K. 1994. Autoantibody responses to the "native" 52-kDa SS-A/Ro protein in neonatal lupus syndromes, systemic lupus erythematosus, and Sjogren's syndrome. J. Immunol. 152:3675-3684.

47. Buyon, J.P., Slade, S.G., Chan, E.K., Tan, E.M., and Winchester, R. 1990. Effective separation of the 52 $\mathrm{kDa} S \mathrm{SA} /$ Ro polypeptide from the $48 \mathrm{kDa} \mathrm{SSB} / \mathrm{La}$ polypeptide by altering conditions of polyacrylamide gel electrophoresis. J. Immunol. Methods. 129:207-210.

48. Caricchio, R., McPhie, L., and Cohen, P.L. 2003. Ultraviolet $\mathrm{B}$ radiation-induced cell death: critical role of ultraviolet dose in inflammation and lupus autoantigen redistribution. J. Immunol. 171:5778-5786.

49. Koninger, J., et al. 2005. Phosphatidylserine receptor in chronic pancreatitis: evidence for a macrophage independent role. Ann. Surg. 241:144-151.

50. Bave, U., et al. 2003. Fc gamma RIIa is expressed on natural IFN-alpha-producing cells (plasmacytoid dendritic cells) and is required for the IFN-alpha production induced by apoptotic cells combined with lupus IgG. J. Immunol. 171:3296-3302. 